Rev. 0

\title{
IMPACT OF CURING TEMPERATURE ON THE SATURATED LIQUID PERMEABILITY OF SALTSTONE
}

\author{
J. R. Harbour and M. F. Williams
}

Savannah River National Laboratory

February 2011

Savannah River National Laboratory

Savannah River Nuclear Solutions

Aiken, SC 29808 


\section{DISCLAIMER}

This work was prepared under an agreement with and funded by the U.S. Government. Neither the U.S. Government or its employees, nor any of its contractors, subcontractors or their employees, makes any express or implied: 1 . warranty or assumes any legal liability for the accuracy, completeness, or for the use or results of such use of any information, product, or process disclosed; or 2. representation that such use or results of such use would not infringe privately owned rights; or 3. endorsement or recommendation of any specifically identified commercial product, process, or service. Any views and opinions of authors expressed in this work do not necessarily state or reflect those of the United States Government, or its contractors, or subcontractors.

\section{Printed in the United States of America}

Prepared For

U.S. Department of Energy 
Rev. 0

Key Words: Hydraulic Conductivity Young's Modulus Microstructure

Retention: Permanent

\title{
IMPACT OF CURING TEMPERATURE ON THE SATURATED LIQUID PERMEABILITY OF SALTSTONE
}

\author{
J. R. Harbour and M. F. Williams
}

Savannah River National Laboratory

February 2011

Savannah River National Laboratory

Savannah River Nuclear Solutions

Aiken, SC 29808

Prepared for the U.S. Department of Energy Under

Contract Number DE-AC09-08SR22470

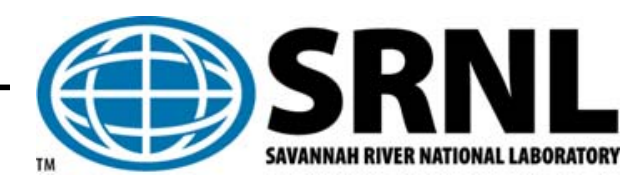




\section{REVIEWS AND APPROVALS}

\section{AUTHORS:}

J. R. Harbour, SRNL, Engineering Process Development

Date

M. F. Williams, SRNL, Engineering Process Development

Date

\section{TECHNICAL REVIEWERS:}

M. M. Reigel, SRNL, Engineering Process Development

Date

\section{APPROVERS}

A. B. Barnes, SRNL, Manager, Engineering Process Development

Date

S. L. Marra, SRNL, Manager, E\&CPT Research Programs

Date 


\section{EXECUTIVE SUMMARY}

This report focuses on the impact of curing temperature on the performance properties of simulated Saltstone mixes. The key performance property of interest is saturated liquid permeability (measured as hydraulic conductivity), an input to the Performance Assessment (PA) modeling for the Saltstone Disposal Facility (SDF). Therefore, the current study was performed to measure the dependence of saturated hydraulic conductivity on curing temperature of Saltstone mixes, to correlate these results with measurements of Young's moduli on the same samples and to compare the Scanning Electron Microscopy (SEM) images of the microstructure at each curing temperature in an effort to associate this significant changes in permeability with changes in microstructure.

This work demonstrated that the saturated liquid permeability of Saltstone mixes depends significantly on the curing temperature. As the curing temperature increases, the hydraulic conductivity can increase over three orders of magnitude from roughly $10^{-9} \mathrm{~cm} / \mathrm{sec}$ to $10^{-6} \mathrm{~cm} / \mathrm{sec}$ over the temperature range of $20^{\circ} \mathrm{C}$ to $80^{\circ} \mathrm{C}$. Although an increased aluminate concentration (at $0.22 \mathrm{M}$ ) in the ARP/MCU waste stream improves (decreases) saturated permeability for samples cured at lower temperatures, the permeabilities for samples cured at $60{ }^{\circ} \mathrm{C}$ to $80^{\circ} \mathrm{C}$ are the same as the permeabilities measured for an equivalent mix but with lower aluminate concentration.

Furthermore, it was demonstrated that the unsaturated flow apparatus (UFA) system can be used to measure hydraulic conductivity of Saltstone samples. The permeability results obtained using the UFA centrifuge system were equivalent within experimental error to the conventional permeameter results (the falling head method) obtained at MACTEC. In particular the UFA technique is best suited for the range of hydraulic conductivities between $10^{-10} \mathrm{~cm} / \mathrm{sec}$ to $10^{-6}$ $\mathrm{cm} / \mathrm{sec}$.

Measurements of dynamic Young's moduli (E) for these mixes revealed a correlation between E and hydraulic conductivity. Therefore, it is possible to use $\mathrm{E}$ values to estimate the values of hydraulic conductivity. Measurement of Young's modulus is much easier than the measurement of permeability of Saltstone mixes and facilitates the measurement of the time dependence hydraulic conductivity.

The results presented in this report show that changes in permeability as a function of curing temperature appear to be related to microstructural changes in the cured Saltstone mixes. Backscattered electron microscopy images revealed significant differences between the samples cured at different temperatures. 
TABLE OF CONTENTS

EXECUTIVE SUMMARY ……………………………........................................

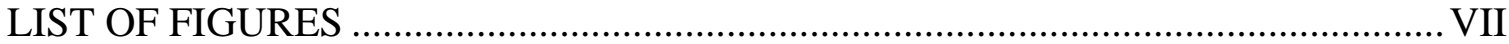

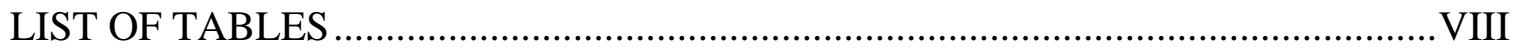

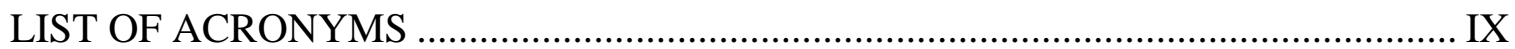

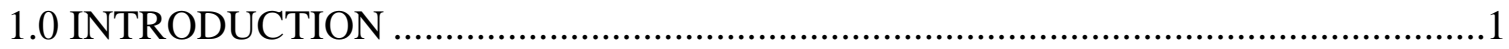

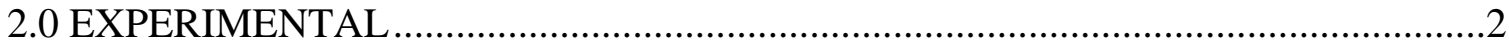

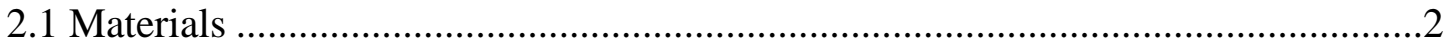

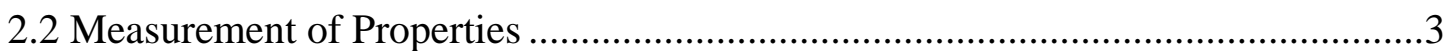

2.3 Curing at Higher Temperatures .............................................................................

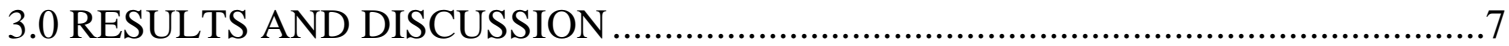

3.1 Hydraulic Conductivities -Low Aluminate Mixes.....................................................

3.2 Hydraulic Conductivities -High Aluminate Mixes ...................................................

3.3 Dynamic Young’s Modulus - All Mixes.............................................................10

3.4 Correlation - Young's Modulus and Hydraulic Conductivity..................................11

3.5 Microstructure - Scanning Electron Microscopy ………........................................12

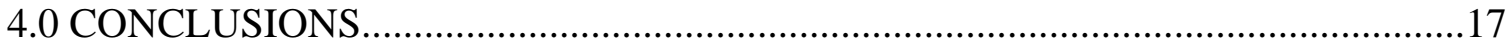

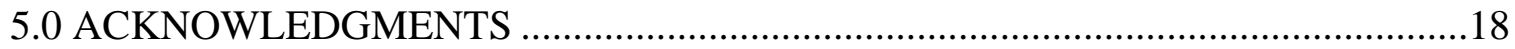

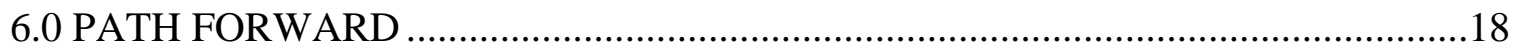

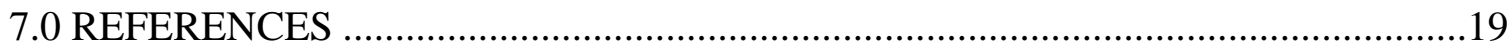




\section{LIST OF FIGURES}

Figure 2.2-1 The UFA system for measuring permeability (hydraulic conductivity) ................... 3 Figure 2.2-2 Photograph of the UFA system. The permeant is fed gravitationally or by use of the pumps shown on the right.

Figure 2.2-3 Photograph of the UFA system with the top open. The permeant is fed through the tubing while the rotor is spinning.

Figure 2.2-4 Components of the stainless steel holder for the grout sample (a - d) and an

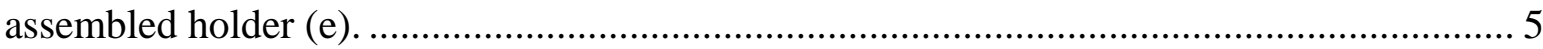

Figure 2.2-5 Sample holder for the centrifuge: the grout sample in the cylinder (a) is placed into the stainless steel holder (b), the bottom collection cup (c) connected to the holder and the top (d) to make the final UFA sample setup (e)....................................................... 6

Figure 3.1-1 Hydraulic conductivities vs. curing temperature for the low aluminate mix........... 7

Figure 3.1-2 Comparison of hydraulic conductivities for equivalent mixes measured by

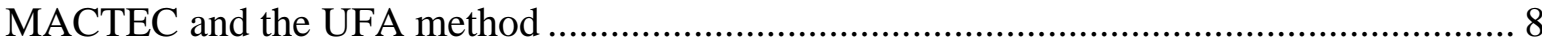

Figure 3.1-3 Rate of pore solution collection as a function of time for two different samples from the identical mix

Figure 3.2-1 Hydraulic conductivities for the high aluminate mix measured after 30 days at different curing temperatures .............................................................................. 10

Figure 3.3-1 Young's modulus (E) for the low and high aluminate mixes measured after 30 days vs. curing temperature.

Figure 3.4-1 Hydraulic conductivity vs. Young's modulus for the low and high aluminate mixes measured after 30 days vs. curing temperature.

Figure 3.5-1 Backscattered SEM image of a polished high aluminate mix sample cured at $40{ }^{\circ} \mathrm{C}$

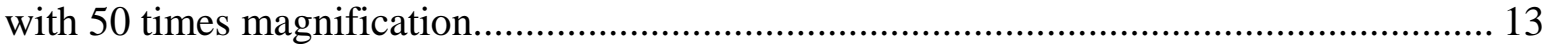

Figure 3.5-2 Backscattered SEM image of a polished high aluminate mix sample cured at $40{ }^{\circ} \mathrm{C}$ with 500 times magnification.............................................................................. 13

Figure 3.5-3 Backscattered SEM image of a polished high aluminate mix sample cured at $60{ }^{\circ} \mathrm{C}$

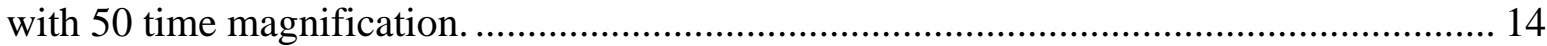

Figure 3.5-4 Backscattered SEM image of a polished high aluminate mix cured at $60{ }^{\circ} \mathrm{C}$ with 500 times magnification...................................................................................... 15

Figure 3.5-5 Backscattered SEM image of a fractured surface from a sample of the high aluminate mix cured at $60{ }^{\circ} \mathrm{C}$ with 500 times magnification. 16 
Rev. 0

\section{LIST OF TABLES}

Table 2-1 Saltstone Cementitious Materials and Current Premix Blend...................................... 2

Table 2-2 Compositions of the High and Low Aluminate MCU Simulants................................ 2 
Rev. 0

\section{LIST OF ACRONYMS}

$\begin{array}{ll}\text { ACTL } & \text { Aiken County Technology Laboratory } \\ \text { ASTM } & \text { American Society for Testing and Materials } \\ \text { CBO } & \text { Carbon Burn-Out } \\ \text { CSH } & \text { Calcium Silicate Hydrate } \\ \text { E } & \text { Young's Modulus } \\ \text { FA } & \text { Class F Fly Ash } \\ \text { BFS } & \text { Blast Furnace Slag } \\ \text { DSS } & \text { Decontaminated Salt Solution } \\ \text { MCU } & \text { Modular Caustic Side Solvent Extraction } \\ \text { PC } & \text { Portland Cement } \\ \text { PA } & \text { Performance Assessment } \\ \text { SDF } & \text { Saltstone Disposal Facility } \\ \text { SEM } & \text { Scanning Electron Microscopy } \\ \text { SPF } & \text { Saltstone Production Facility } \\ \text { SRNL } & \text { Savannah River National Laboratory } \\ \text { SRNS } & \text { Savannah River Nuclear Solutions } \\ \text { SRS } & \text { Savannah River Site } \\ \text { UFA } & \text { Unsaturated Flow Apparatus } \\ \text { w/cm } & \text { Water to Cementitious Material Ratio }\end{array}$




\subsection{INTRODUCTION}

At the Saltstone Production Facility (SPF), decontaminated salt solution (DSS) is combined with premix (a mixture of portland cement (PC), blast furnace slag (BFS) and Class F fly ash (FA)) in a Readco mixer to produce fresh (uncured) Saltstone. After transfer to the Saltstone Disposal Facility (SDF) the hydration reactions initiated during the mixing of the premix and salt solution continue during the curing period to produce the hardened waste form product. The saturated hydraulic conductivity of the cured waste form is a key property input into the Performance Assessment (PA) models used to predict radionuclide release. Historically, the values of saturated hydraulic conductivity used for Saltstone mixes were determined for samples that had been cured at room temperature $\left(20^{\circ} \mathrm{C}\right.$ to $\left.25^{\circ} \mathrm{C}\right)$. However, a number of studies have shown that the solid grout properties (e.g., dynamic Young's modulus and compressive strength) depended significantly on curing temperature [1-4]. A preliminary study showed that the hydraulic conductivity increased by 700 times for a sample cured at $60{ }^{\circ} \mathrm{C}$ vs. $20{ }^{\circ} \mathrm{C}$ [5]. The curing temperature of Saltstone is relevant since the temperature of Saltstone within the vault can reach values greater than $80{ }^{\circ} \mathrm{C}$ for extended periods of time during the curing process. Therefore, the current study was performed to measure the dependence of saturated hydraulic conductivity on curing temperature of Saltstone mixes, to correlate these results with measurements of Young's moduli and to compare the Scanning Electron Microscopy (SEM) images of the microstructure at each curing temperature in an effort to associate this significant change in permeability with a change in microstructure [6]. A parallel study, funded by the Liquid Waste Customer, is being performed with the goal of ensuring that values of this property introduced as input to the PA are representative of the Saltstone in the vaults [7].

The measurement of hydraulic conductivity is inherently difficult [8]. There are (1) sample-tosample, (2) batch-to-batch, (3) lab-to-lab, and (4) technique-to-technique variations that are typically on the order of 0.5 to 1 order of magnitude but often higher. The ASTM method (D5084-03) using a permeameter indicates that no round robin testing has been performed to quantify the variation in results between laboratories for the same technique. In addition, no standard exists from which to measure accuracy. The measurements become even more difficult and show greater variance as the hydraulic conductivity decreases. The history of measurement of hydraulic conductivity for Saltstone mixes reveals the wide range of measured values [9]. The latest measurements for Saltstone, cured at room temperature, show values in the range of $10^{-9}$ $\mathrm{cm} / \mathrm{sec}$ and it is this value that is currently used as input to the PA [5].

Due to the difficulties in measurement of permeability, an independent technique was investigated for measurement of hydraulic conductivity using the ASTM based unsaturated flow apparatus (UFA) for comparison to the conventional falling head permeameter. The UFA method, if successful, could then be used for in-house measurement of hydraulic conductivity of Saltstone samples. If the hydraulic conductivity can be correlated with Young's modulus (E), then measurement of E values could also be done in-house to evaluate hydraulic conductivity [14]. Measurement of $E$ is much simpler than measuring hydraulic conductivity and can be readily performed as a function of time [3]. It also has the potential for use with radioactive samples. 


\subsection{EXPERIMENTAL}

\subsection{Materials}

The cementitious materials were obtained from Saltstone in five gallon containers and are listed in Table 2-1. These materials were specified in a contract for Saltstone cementitious materials and arrived with the delivery of the cementitious materials to Saltstone. The materials were transferred to smaller high-density polyethylene bottles at Aiken County Technology Laboratory (ACTL) and tightly sealed. Maintaining these materials in a tightly sealed container limits the exposure of the materials to humid air and hydration of the materials prior to use. Table 2-1 also contains the wt \% contribution of each material used to make the premix. The fly ash used in this study was a material that had been thermally treated by the vendor to remove most of the carbon and ammonia (carbon burnout or CBO fly ash).

Table 2-1 Saltstone Cementitious Materials and Current Premix Blend

\begin{tabular}{|c|c|c|c|}
\hline Material & Category & Vendor & Premix wt \% \\
\hline Portland Cement & Type II & Holcim & 10 \\
\hline Blast Furnace Slag & Grade I & Holcim & 45 \\
\hline Fly Ash & Class F & SEFA & 45 \\
\hline
\end{tabular}

Two simulants were used to represent the low level waste stream to be treated at the Saltstone Production Facility (SPF). The streams are based on the Modular Caustic Side Solvent Extraction (MCU) projections with one stream having low aluminate concentration $(0.05 \mathrm{M})$ and the other a higher level of aluminate $(0.22 \mathrm{M})$. The compositions of the two waste streams are provided in Table 2-2.

Table 2-2 Compositions of the High and Low Aluminate MCU Simulants

\begin{tabular}{|c|c|c|}
\hline Material & Low Aluminate & High Aluminate \\
\hline $\mathrm{NaOH}$ (free OH) & 1.80 & 1.80 \\
\hline $\mathrm{NaNO}_{3}$ & 2.36 & 2.36 \\
\hline $\mathrm{NaNO}_{2}$ & 0.55 & 0.55 \\
\hline $\mathrm{Na}_{2} \mathrm{CO}_{3}$ & 0.18 & 0.18 \\
\hline $\mathrm{Na}_{2} \mathrm{SO}_{4}$ & 0.06 & 0.06 \\
\hline $\mathrm{Al}\left(\mathrm{NO}_{3}\right)_{3} \cdot 9 \mathrm{H}_{2} \mathrm{O}$ & 0.05 & 0.22 \\
\hline $\mathrm{Na}_{3} \mathrm{PO}_{4} \cdot 12 \mathrm{H}_{2} \mathrm{O}$ & 0.01 & 0.01 \\
\hline
\end{tabular}




\subsection{Measurement of Properties}

The measurements of dynamic Young's modulus and cured grout densities were performed by the methods described previously [3-4]. Measurements of hydraulic conductivity were made using (1) a conventional permeameter (ASTM D5084-03, Method F, Constant Volume, Falling Head) located at MACTEC in Atlanta and (2) a centrifuge method using the UFA steady state centrifuge method (ASTM D6527) located at ACTL. Permeability and hydraulic conductivity are related as described in a previous report [9].

The UFA system is shown schematically in Figure 2.2-1. This system maintains permeant flow during centrifugation. The hydraulic conductivity can be calculated from the flow of liquid through the porous medium over time. Figures 2.2-2 and 2.2-3 are photographs of the UFA system with the centrifuge top down and open. For the permeability measurements performed as part of this task, the permeant (water) was fed gravitationally to the sample which promotes and maintains saturation of the samples.

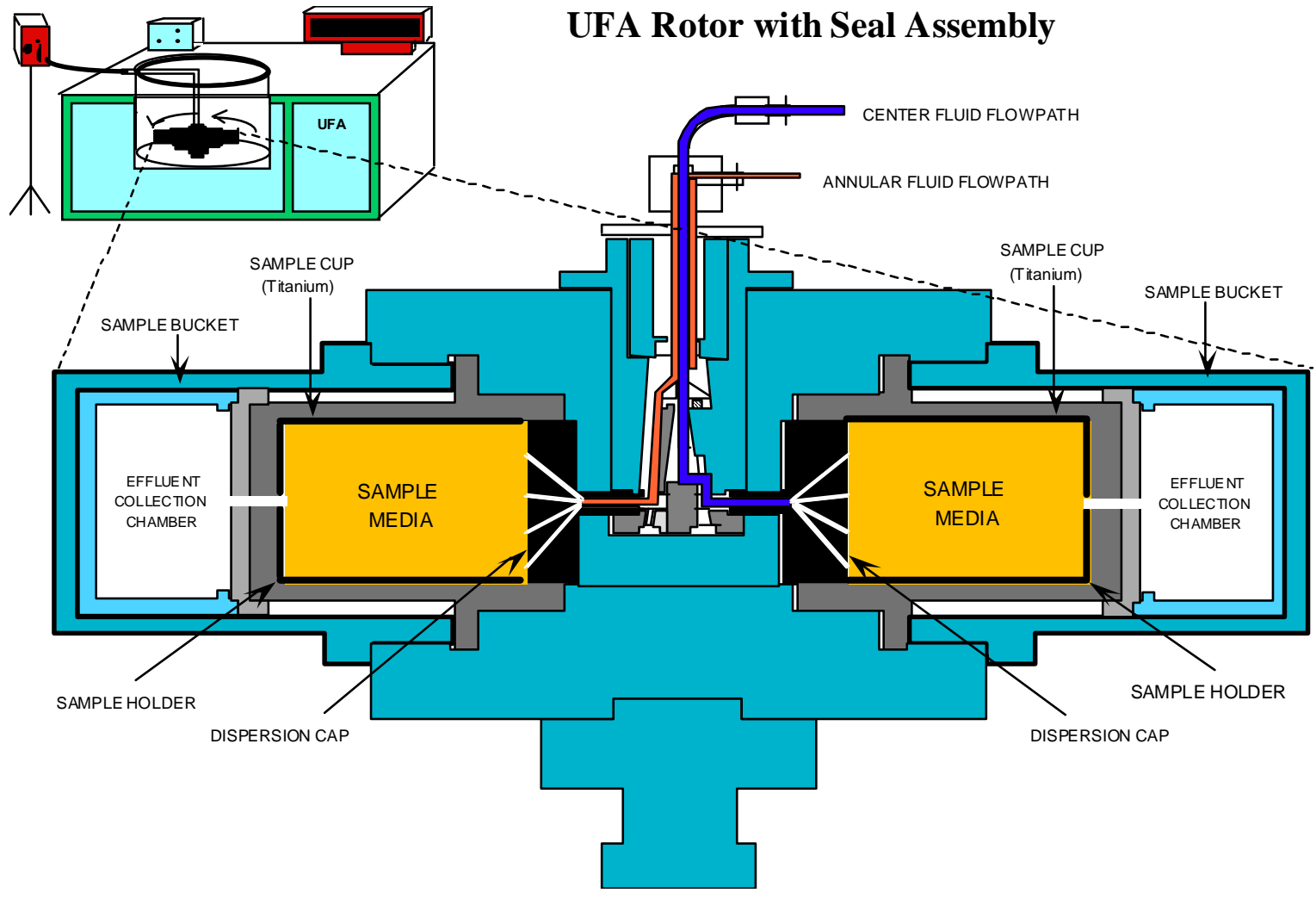

Figure 2.2-1 The UFA system for measuring permeability (hydraulic conductivity) 
Rev. 0

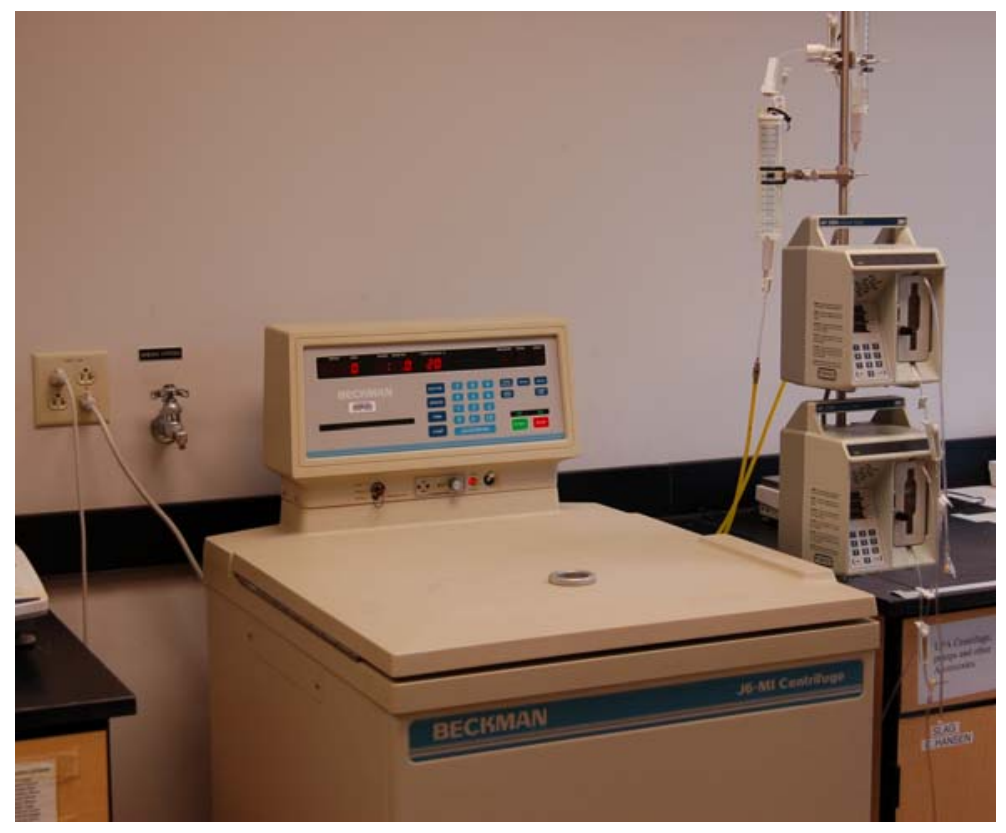

Figure 2.2-2 Photograph of the UFA system. The permeant is fed gravitationally or by use of the pumps shown on the right.

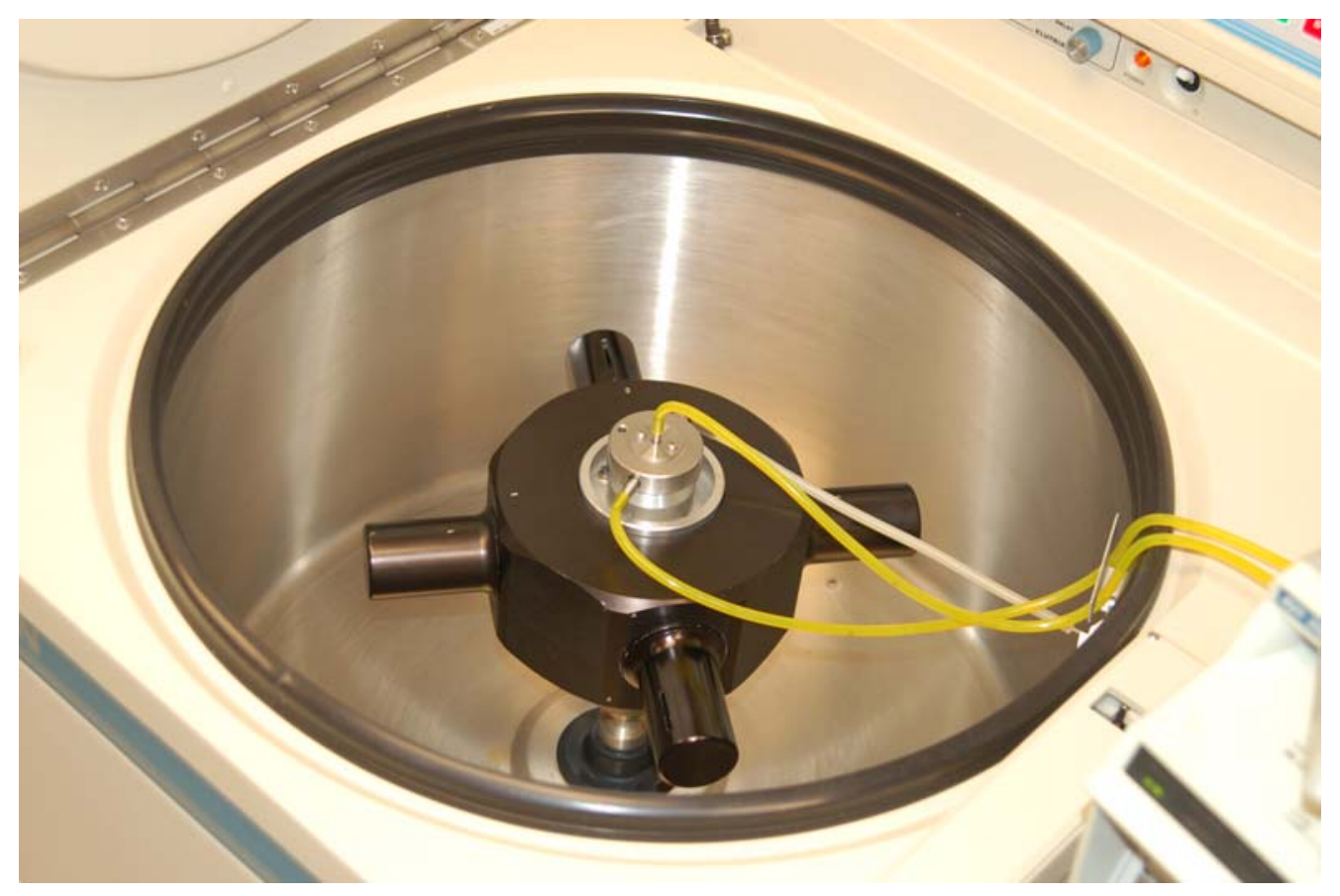

Figure 2.2-3 Photograph of the UFA system with the top open. The permeant is fed through the tubing while the rotor is spinning. 
Figure 2.2-4 shows the cylindrical portion of the sample holder (a) is inserted into the bottom piece (b) and the grout mix is poured into the holder such that there is excess grout on the top surface. The top piece (c) is then loosely placed on the cylinder and the assembled sample holder cured at the selected temperature. Figure 2.2-4 also shows the assembled holder (d) and the grout filled cylinder after curing and disassembly (e). The excess Saltstone in the grout-filled cylinder is removed by filing off the excess grout on both the top and bottom and then inserted into the UFA sample holder (Figure 2.2-5).

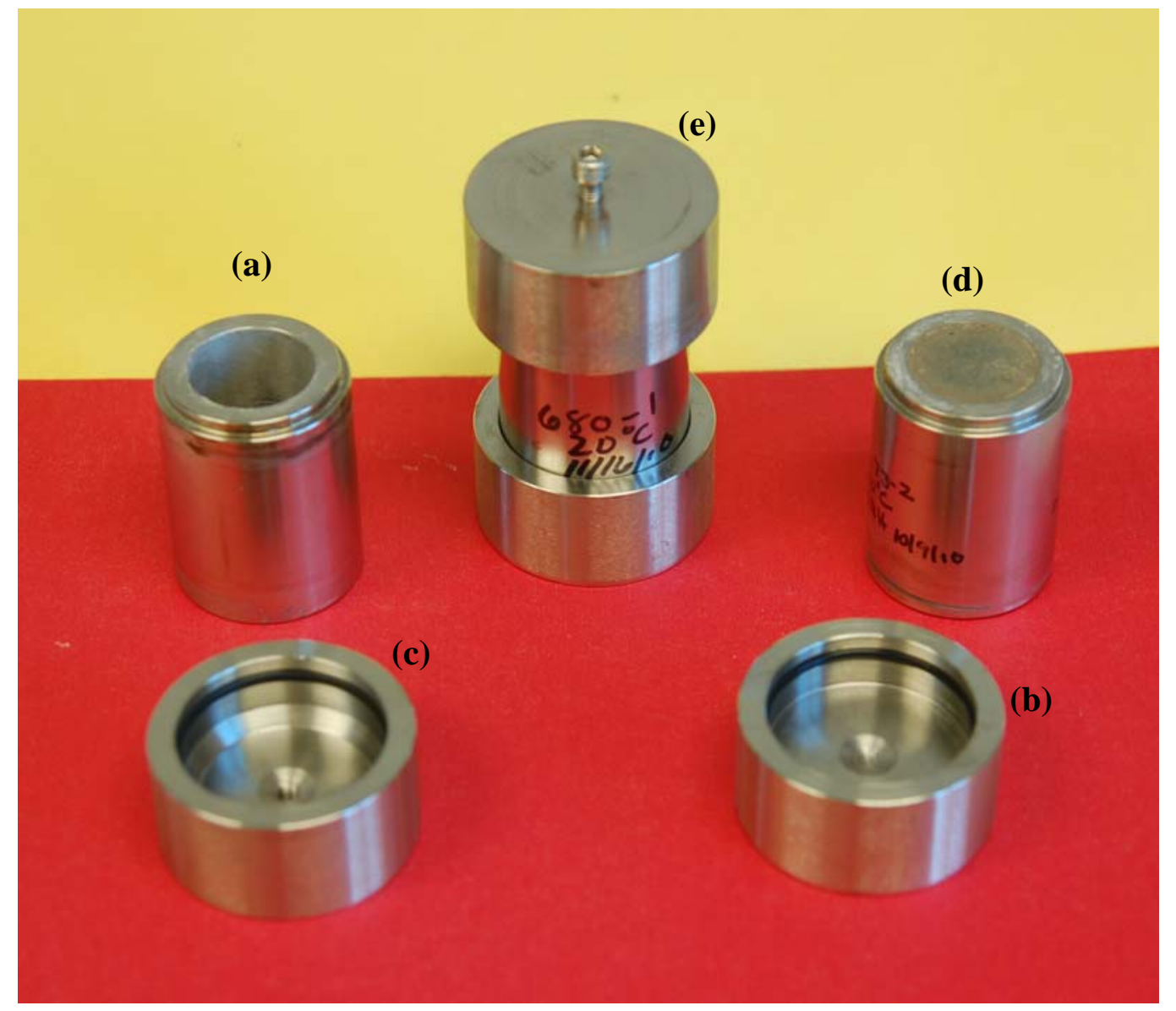

Figure 2.2-4 Components of the stainless steel holder for the grout sample (a - d) and an assembled holder (e). 


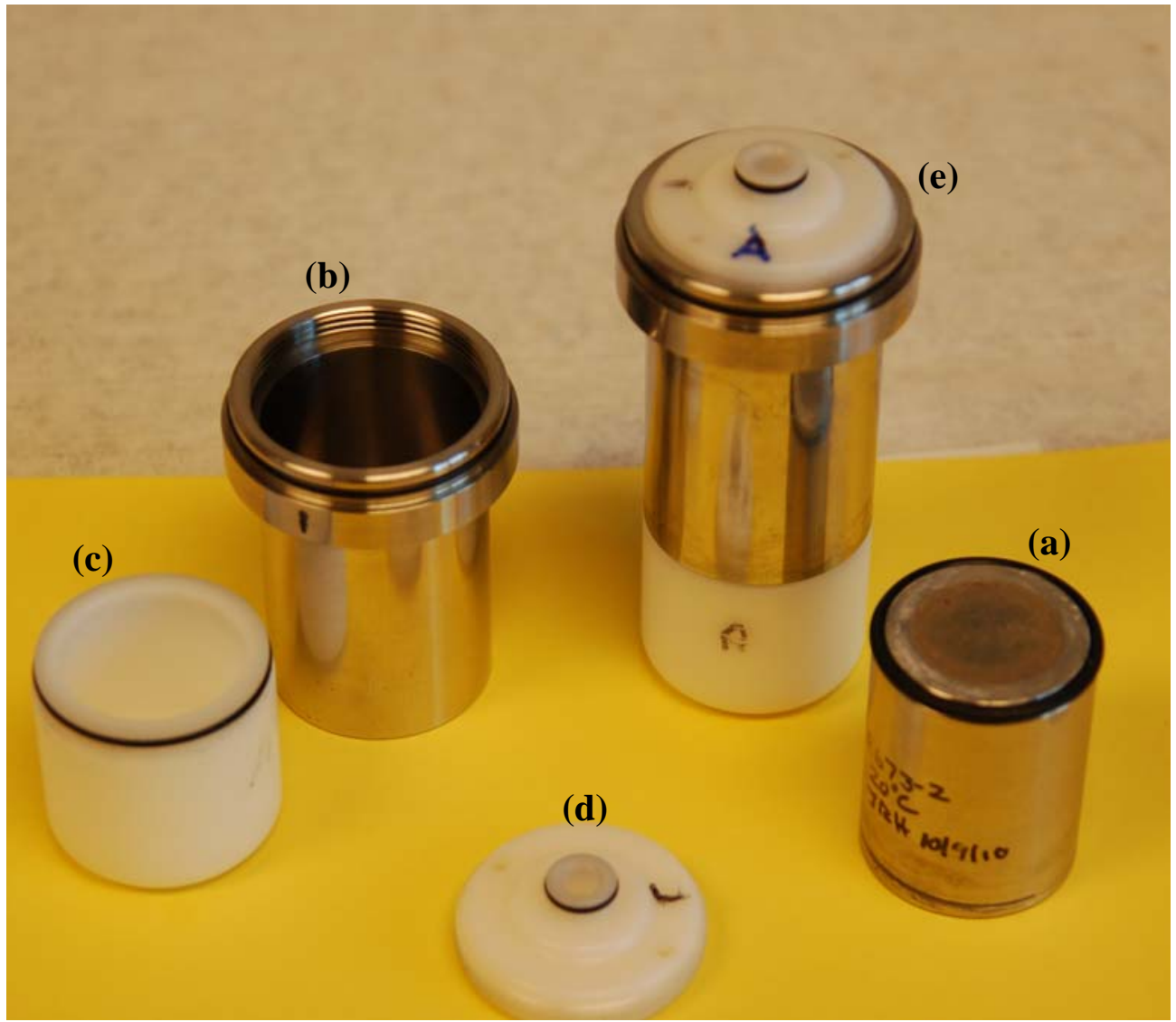

(c)

Figure 2.2-5 Sample holder for the centrifuge: the grout sample in the cylinder (a) is placed into the stainless steel holder (b), the bottom collection cup (c) connected to the holder and the top (d) to make the final UFA sample setup (e).

SEM images were obtained with a Hitachi 3400 Environmental SEM or an Hitachi TM3000.

\subsection{Curing at Higher Temperatures}

Samples were cured at ambient conditions in a controlled laboratory at $20{ }^{\circ} \mathrm{C}$ or at higher temperatures $\left(40{ }^{\circ} \mathrm{C}, 60{ }^{\circ} \mathrm{C}\right.$ and $\left.80{ }^{\circ} \mathrm{C}\right)$ in convention ovens. The samples were cast in plastic cylinders, capped and securely taped. Measurement of the mass of the samples with container, lid and tape were made prior to and after curing to measure any mass loss during curing. At ambient temperature and at $40{ }^{\circ} \mathrm{C}$ curing conditions, essentially no change in the mass before and after curing was noted. For the $60^{\circ} \mathrm{C}$ and the $80^{\circ} \mathrm{C}$ curing conditions, mass losses on the order of 1 to 2 grams were measured for the samples in $3 \times 6$ inch cylinders (total mass of the sample was $\sim 1100$ grams).

The ovens have temperature gradients within the interior of the ovens. Therefore, the range of temperatures for a given sample may be as high as $\pm 5{ }^{\circ} \mathrm{C}$ about a given set temperature. Thermocouples and thermometers were used to measure and control the actual temperatures within the oven. 


\subsection{RESULTS AND DISCUSSION}

The results presented in this report were generated as part of the EM-31 WP 5.2.3 task on Low Activity Waste Forms.

\subsection{Hydraulic Conductivities -Low Aluminate Mixes}

The hydraulic conductivities of the low aluminate mixes cured at 4 different curing temperatures were measured both by MACTEC in Atlanta using a conventional permeameter (ASTM D508403, Method F, Constant Volume, Falling Head) and by the UFA method (ASTM D6527) with steady-state centrifugation at ACTL. The results for the MACTEC measurements are shown in Figure 3.1-1 after 30 days of curing.

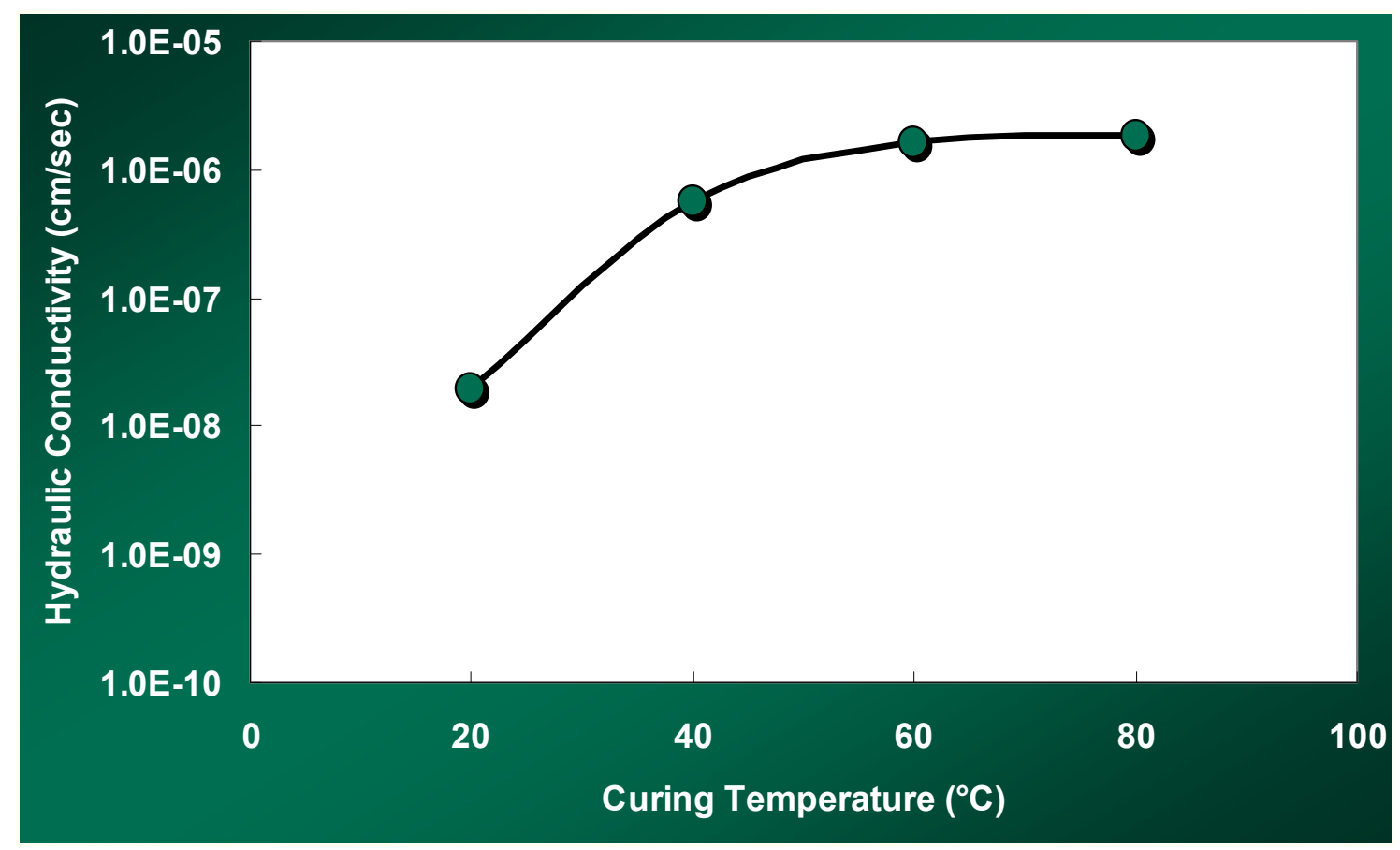

Figure 3.1-1 Hydraulic conductivities vs. curing temperature for the low aluminate mix

With the UFA method, the $20^{\circ} \mathrm{C}$ cured sample was measured after 30 days while the samples cured at the elevated temperatures of $40{ }^{\circ} \mathrm{C}, 60{ }^{\circ} \mathrm{C}$ and $80^{\circ} \mathrm{C}$ were measured after 21 days of curing at temperature. It turns out that in general, curing at higher temperatures for seven days is sufficient to generate a grout that shows no additional change to Young's modulus with time as additional curing continues at either room temperature or higher temperature. However, the sample cured at $40{ }^{\circ} \mathrm{C}$ is in the transitional region and may show further increase in $\mathrm{E}$ as a function of time. The results of the UFA method are shown together with the results obtained by MACTEC in Figure 3.1-2. 


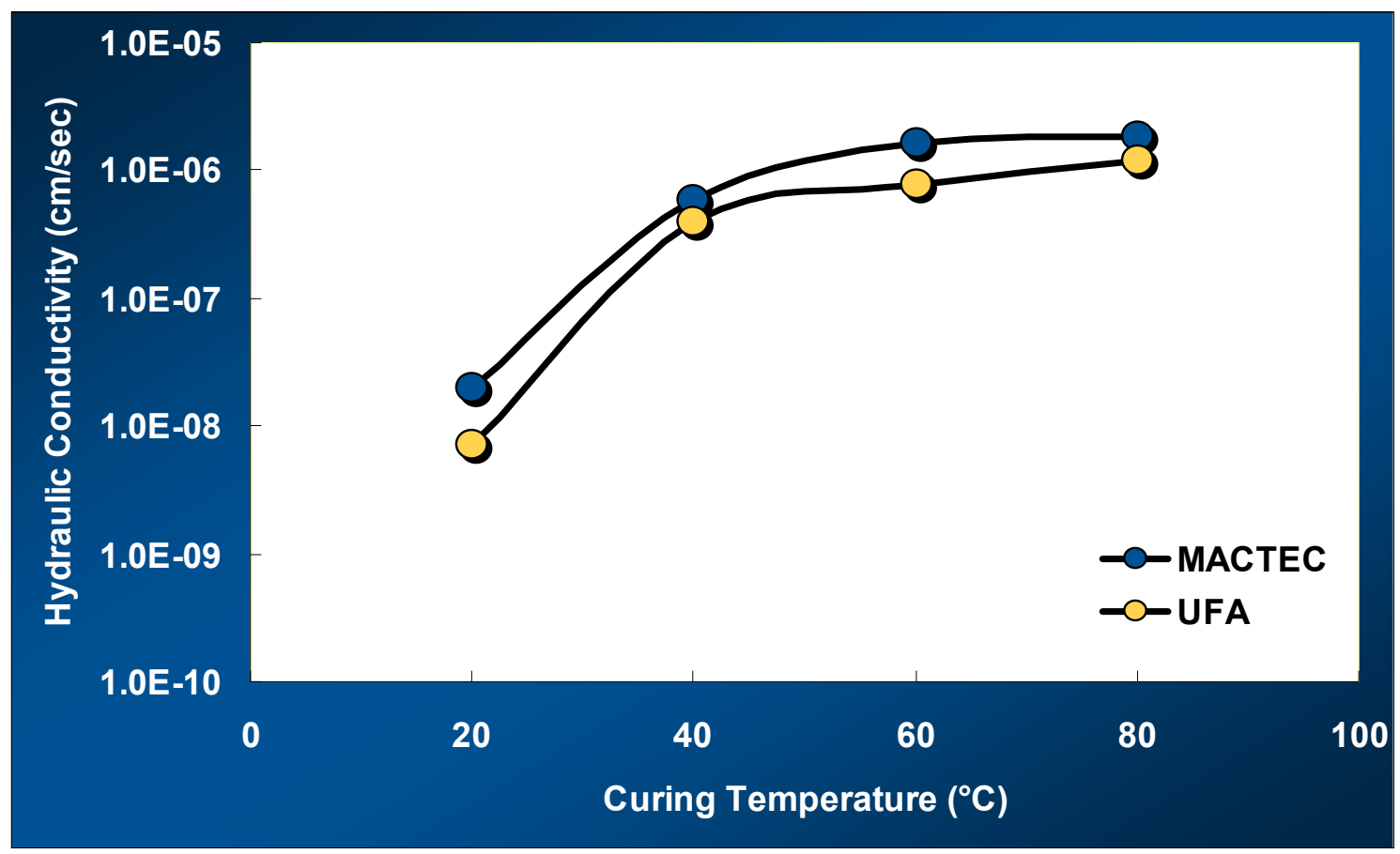

Figure 3.1-2 Comparison of hydraulic conductivities for equivalent mixes measured by MACTEC and the UFA method

There is good agreement between the two methods in measurement of hydraulic conductivity. The UFA method shows a bias with lower values than the results from MACTEC.

Figure 3.1-3 shows the rate of pore solution collected as a function of time with the UFA method for two samples (A and C) from the identical mix. The samples were poured into two separate holders and cured together for 30 days at ambient condition $\left(\sim 20^{\circ} \mathrm{C}\right)$. The rate of pour solution collected stabilized after $\sim 1200$ minutes ( 20 hours). For sample A, the rate after equilibration corresponds to a hydraulic conductivity of $2 \mathrm{E}-08 \mathrm{~cm} / \mathrm{sec}$ whereas for sample B, the rate corresponds to a value of $1 \mathrm{E}-08 \mathrm{~cm} / \mathrm{sec}$. This delay in reaching equilibration may be associated with the time required to achieve saturation of the sample. The difference between the results for samples $\mathrm{A}$ and $\mathrm{C}$ is quite small relative to the variation of this method. This reasoning is consistent with the fact that unsaturated samples have a lower hydraulic conductivity than the saturated samples (Figure 3.1-3). 


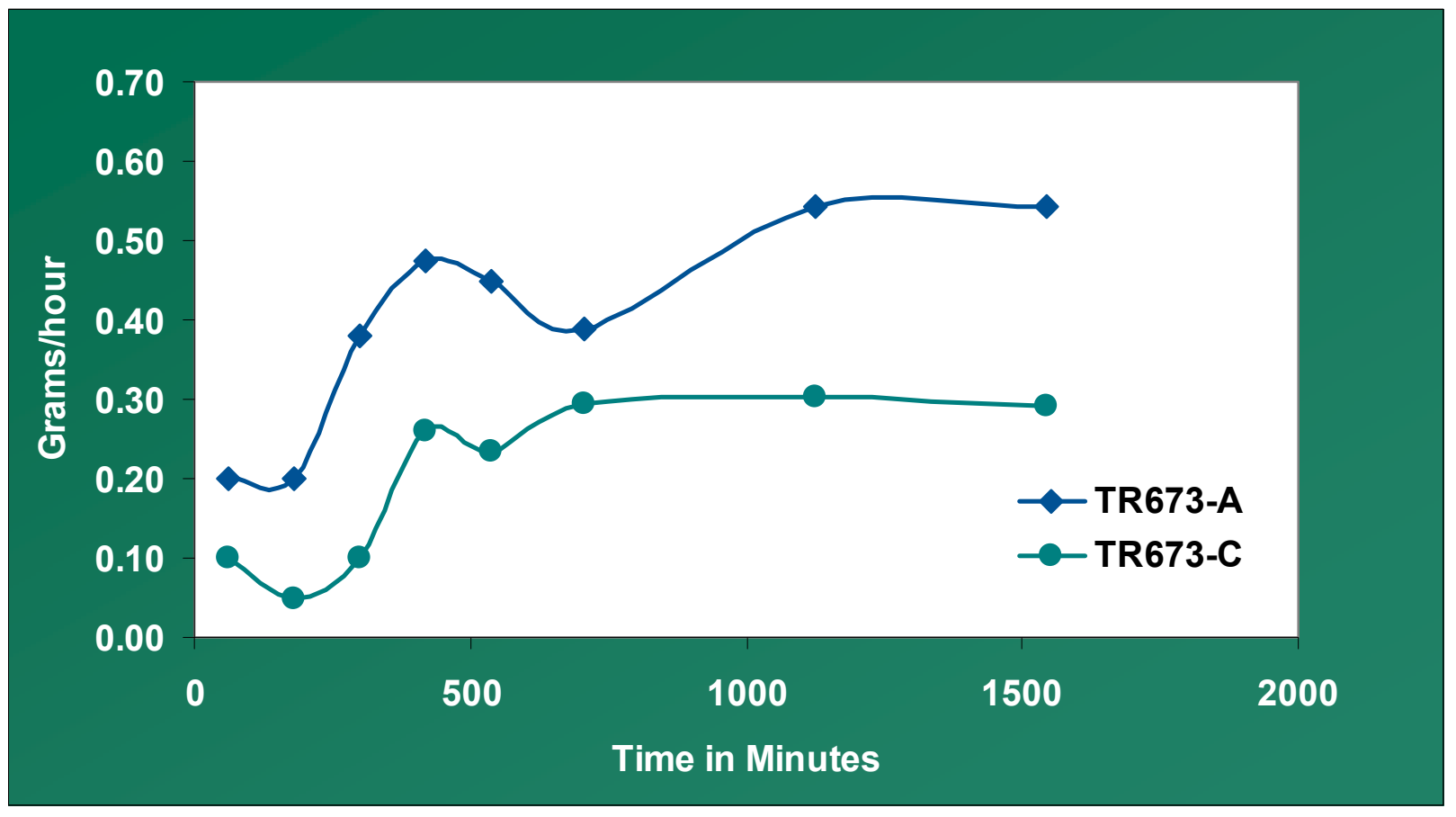

Figure 3.1-3 Rate of pore solution collection as a function of time for two different samples from the identical mix.

\subsection{Hydraulic Conductivities -High Aluminate Mixes}

The hydraulic conductivities of the high aluminate mixes cured at 4 temperatures were measured by MACTEC in Atlanta using a conventional permeameter (ASTM D5084-03, Method F, Constant Volume, Falling Head) The results for the MACTEC measurements are shown in Figure 3.2-1 after 30 days of curing. 


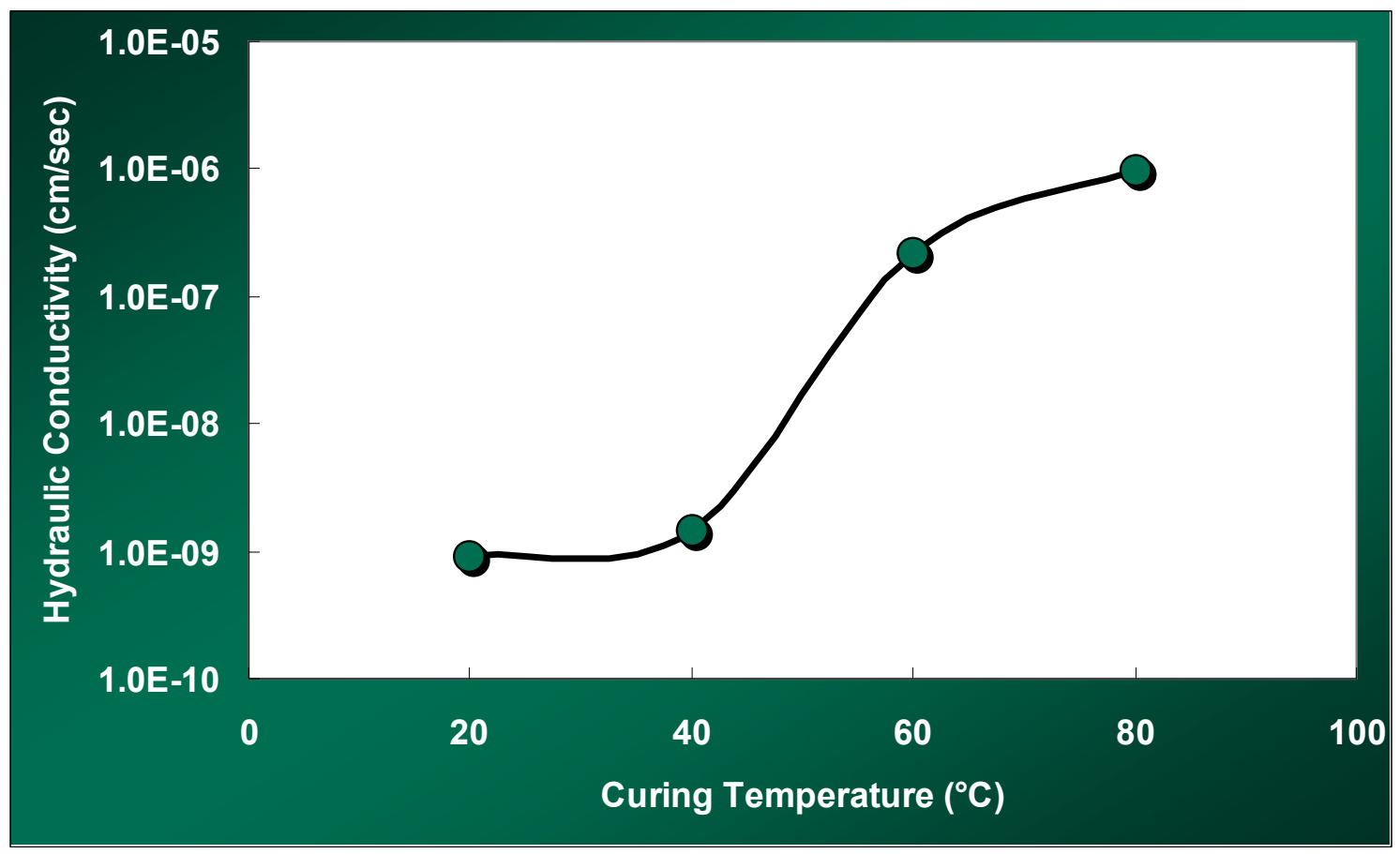

Figure 3.2-1 Hydraulic conductivities for the high aluminate mix measured after 30 days at different curing temperatures

At curing temperatures of $20{ }^{\circ} \mathrm{C}$ or $40{ }^{\circ} \mathrm{C}$, the hydraulic conductivity for the high aluminate mix is lower than the low aluminate mix. This is consistent the higher heat of hydration observed with mixes containing higher levels of aluminate [4]. However, at the higher curing temperatures of $60{ }^{\circ} \mathrm{C}$ and $80^{\circ} \mathrm{C}$, the Saltstone grout has become quite permeable and roughly equivalent to the values of permeability seen for the low temperature mixes at higher curing temperatures.

\subsection{Dynamic Young's Modulus - All Mixes}

The dynamic Young's moduli (the elastic modulus, E) were measured to determine if a correlation between $\mathrm{E}$ and hydraulic conductivity could be established. This is important since the measurement of $\mathrm{E}$ is much easier than measuring hydraulic conductivity and can be done as a function of curing time using the same sample. Young's modulus for both low and high aluminate mixes are plotted vs. curing temperature in Figure 3.3-1. 


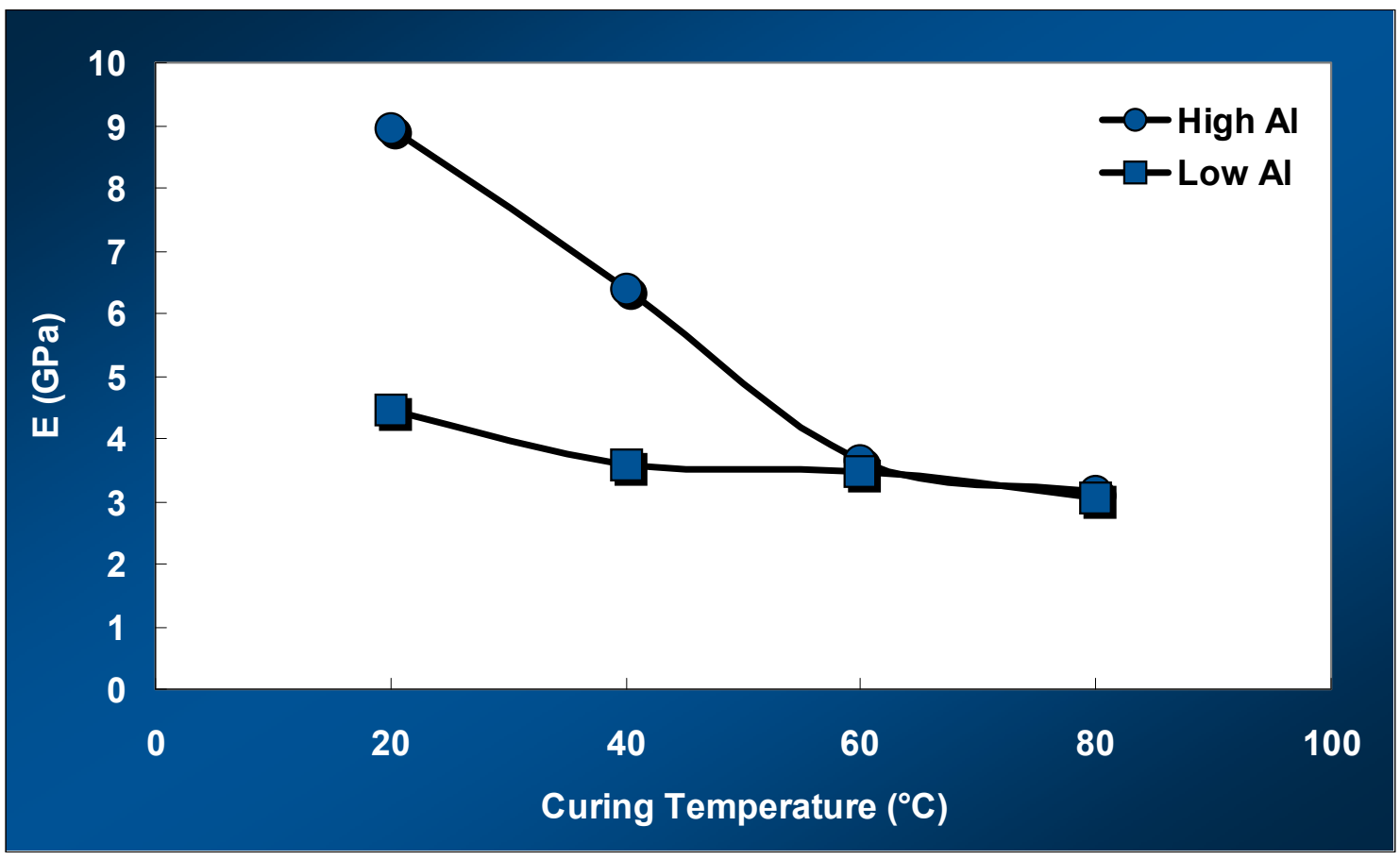

Figure 3.3-1 Young's modulus (E) for the low and high aluminate mixes measured after 30 days vs. curing temperature

For $20{ }^{\circ} \mathrm{C}$ and $40{ }^{\circ} \mathrm{C}$ curing, the higher aluminate mix has higher $\mathrm{E}$ values. However, the $\mathrm{E}$ values for the low and high aluminate mixes become identical at higher curing temperatures.

\subsection{Correlation - Young's Modulus and Hydraulic Conductivity}

The hydraulic conductivity values vs. the E values for both low and high aluminate mixes are plotted in Figure 3.4-1 and include an additional point from a previous study [5]. This plot shows that low values of $\mathrm{E}$ associate well with high values of hydraulic conductivity. A concurrent task with the Site customer is being performed in which 27 mixes have been and will continue to be batched and tested to measure hydraulic conductivity and dynamic Young's modulus. When this additional data is available, they will be combined with the data from this report and a statistically derived empirical fit established to quantify the correlation and provide a model through which hydraulic conductivity can be predicted from Young's Modulus. 


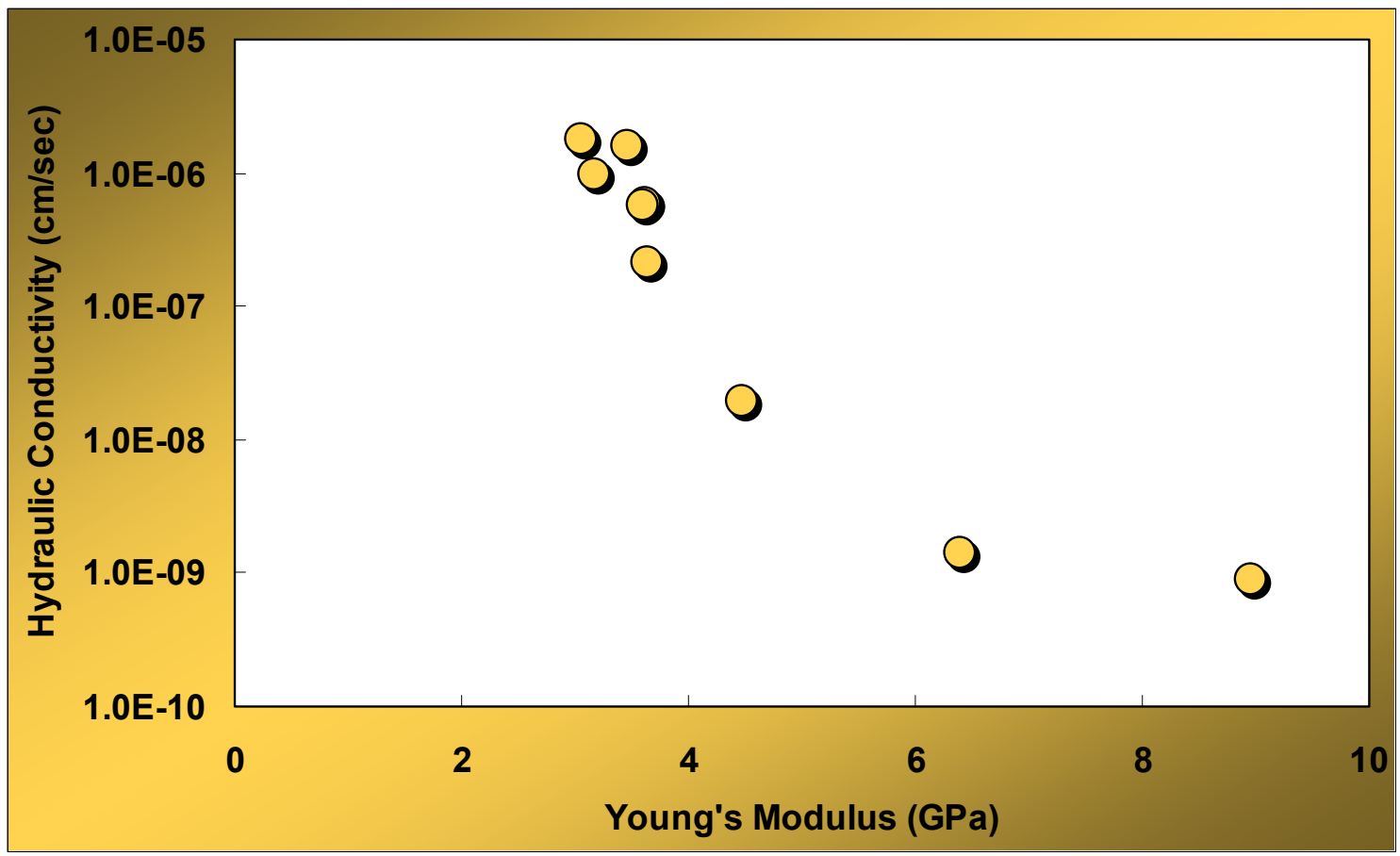

Figure 3.4-1 Hydraulic conductivity vs. Young's modulus for the low and high aluminate mixes measured after 30 days vs. curing temperature.

\subsection{Microstructure - Scanning Electron Microscopy}

The significant increase (several orders of magnitude) in hydraulic conductivity for the mixes cured at higher temperatures most likely results from microstructural differences. In an effort to determine what microstructural changes may have occurred, an SEM study was initiated. The images were obtained at the Clemson Microscopy Facility of the Advanced Materials Research Laboratory.

Figures 3.5-1 and 3.5-2 (50X and 500X, respectively) show typical SEM images of a grout cured at lower temperatures $\left(40^{\circ} \mathrm{C}\right.$ for the high aluminate mix). Unreacted slag (angular particles) and fly ash (circular particles) are evident. 


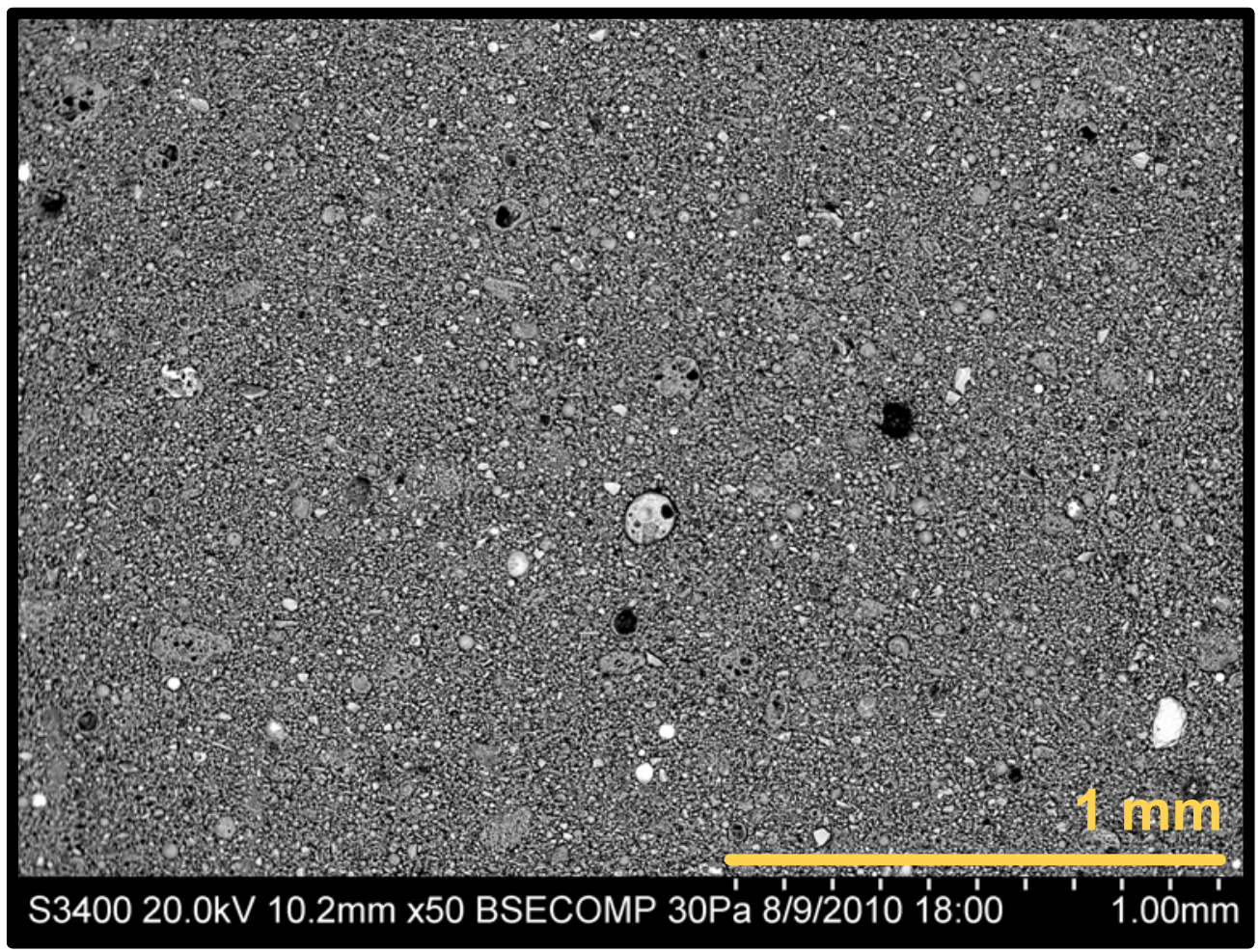

Figure 3.5-1 Backscattered SEM image of a polished high aluminate mix sample cured at $40{ }^{\circ} \mathrm{C}$ with 50 times magnification.

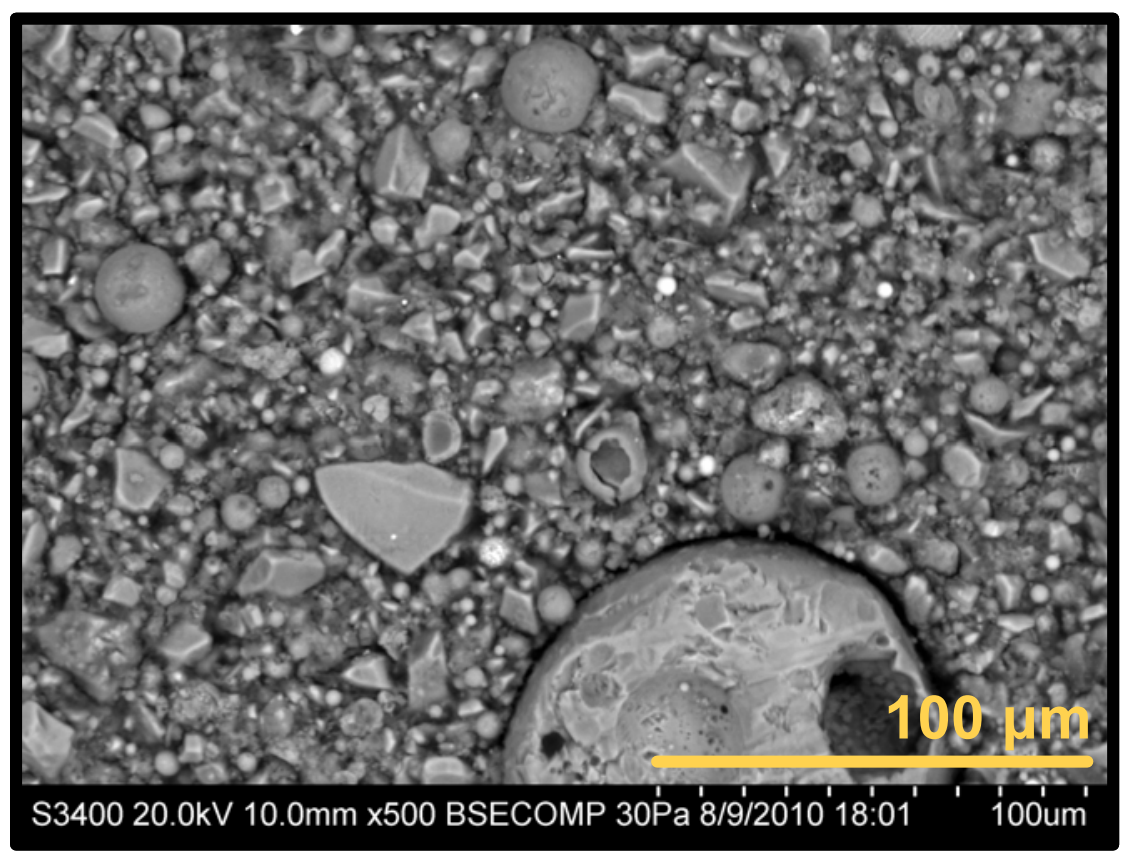

Figure 3.5-2 Backscattered SEM image of a polished high aluminate mix sample cured at $40{ }^{\circ} \mathrm{C}$ with 500 times magnification. 
Figure 3.5-3 shows the SEM image of a polished sample of the same mix cured at $60{ }^{\circ} \mathrm{C}$. The microstructure is significantly different than that shown in Figure 3.5-1. There are significantly larger particles in the microstructure that is causing porosity between the large, ribbon-like particles and the smaller particles. Figure 3.5-4 shows the same $60{ }^{\circ} \mathrm{C}$ cured sample at 500 times magnification. There are ribbons apparently emanating from fly ash and slag particles; however more work must be performed to determine this. Figure 3.5-3 can be contrasted with the image shown in Figure 3.5-2 revealing a different microstructure for the same mix at the two curing temperatures.

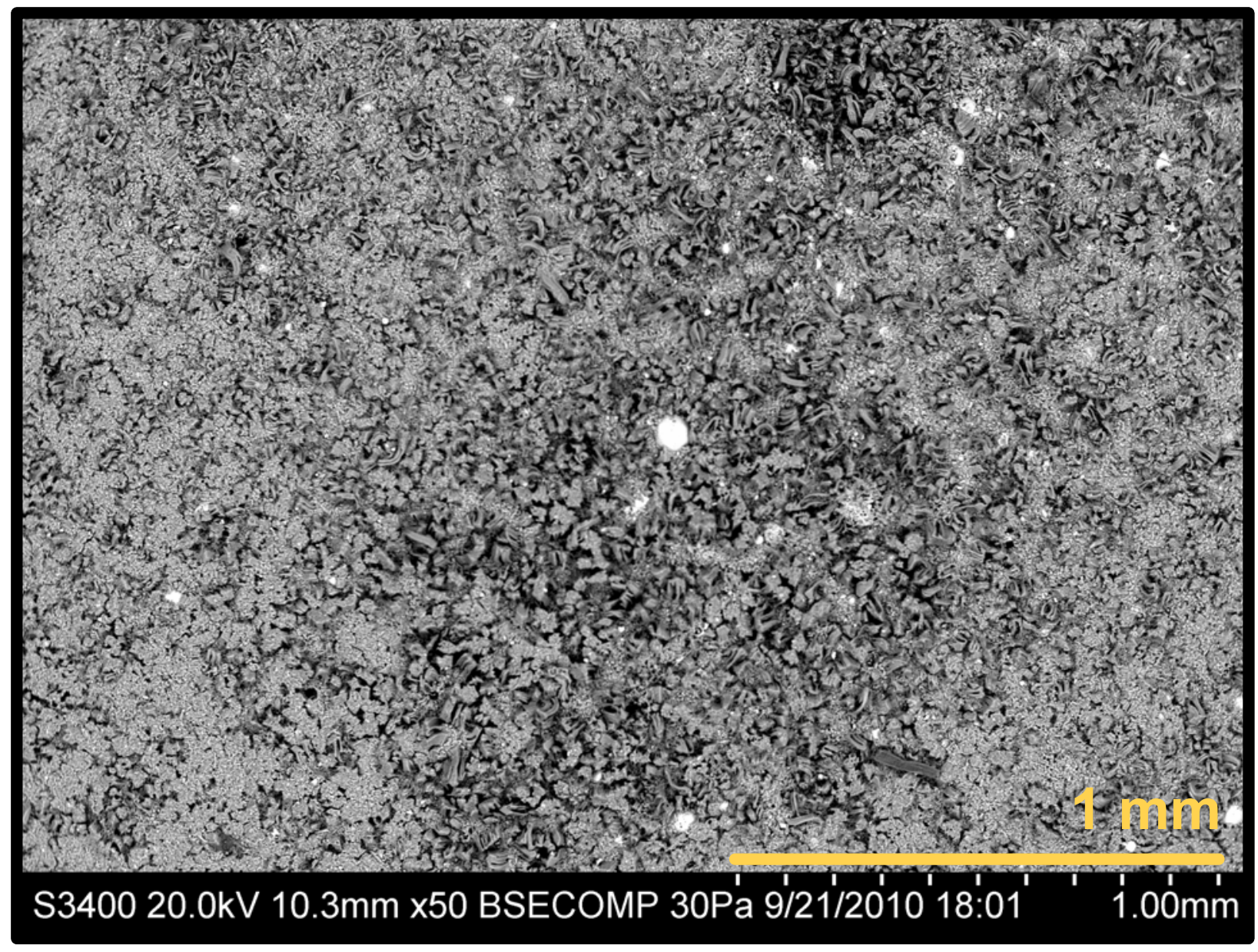

Figure 3.5-3 Backscattered SEM image of a polished high aluminate mix sample cured at $60{ }^{\circ} \mathrm{C}$ with 50 time magnification. 


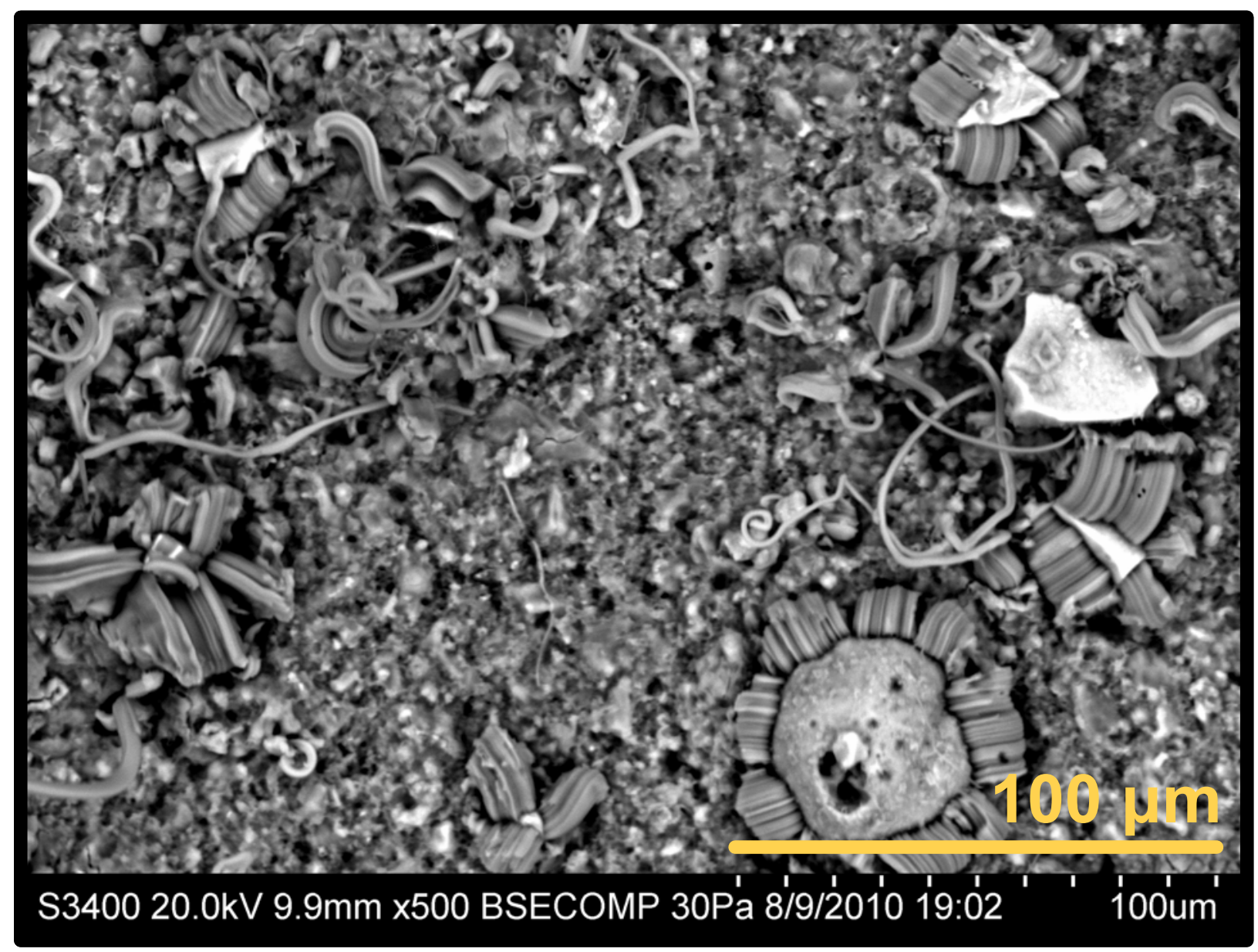

Figure 3.5-4 Backscattered SEM image of a polished high aluminate mix cured at $60{ }^{\circ} \mathrm{C}$ with 500 times magnification.

Based on Figures 3.5-3 and 3.5-4, it appears the $60{ }^{\circ} \mathrm{C}$ cured samples have a greater porosity and consequently higher permeability than the $40{ }^{\circ} \mathrm{C}$ samples. However, this has not been verified yet and further work is being performed to determine the permeability of these samples. It can be concluded that both the microstructure and hydraulic conductivity change considerably with curing temperature but further work is required to establish the connection between microstructure and permeability.

Figure 3.5-5 shows the SEM image for a sample from the same mix cured at $60{ }^{\circ} \mathrm{C}$ that had been fractured rather than polished. The fractured surface provides more insight into the orientation size of the ribbon shaped particles. 


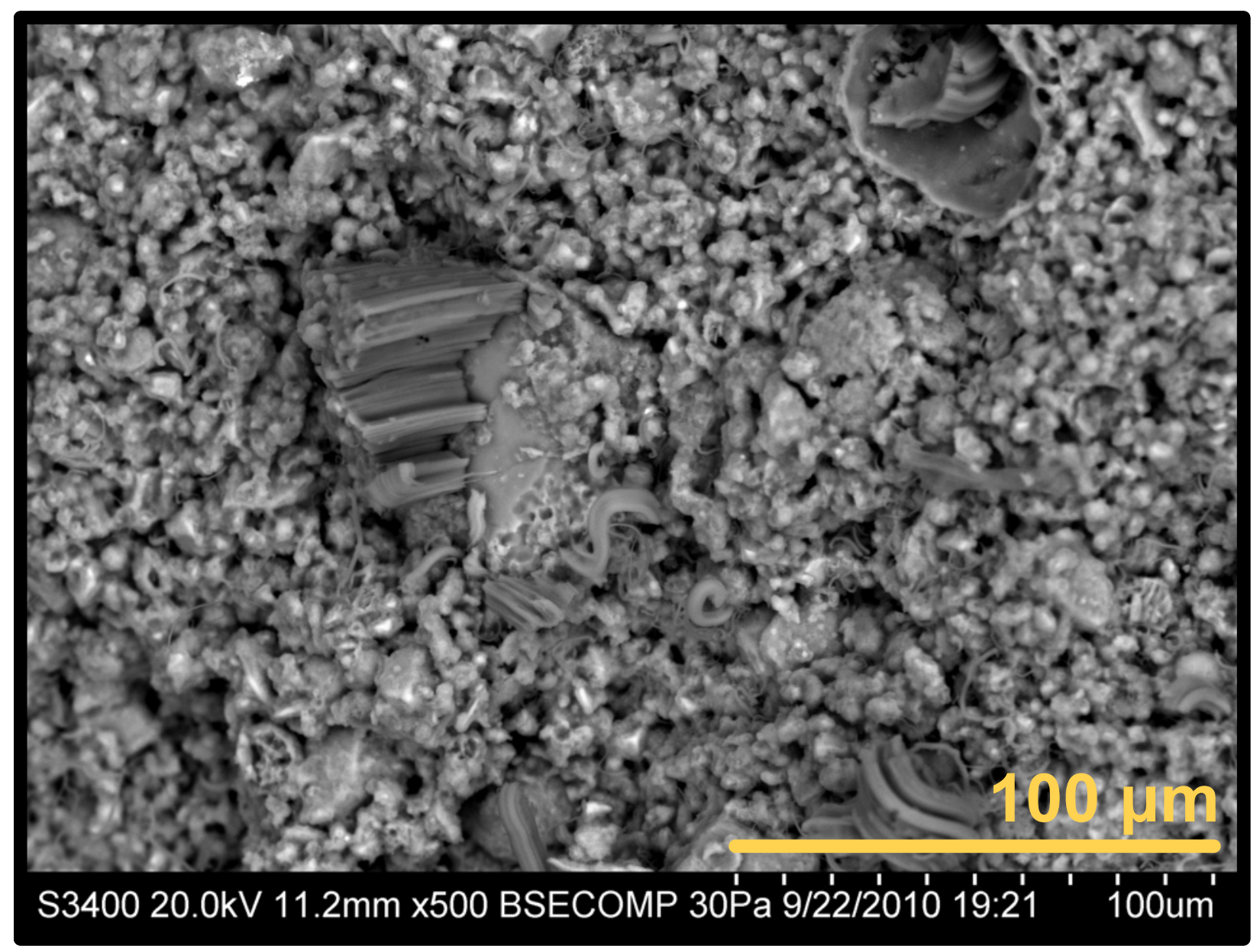

Figure 3.5-5 Backscattered SEM image of a fractured surface from a sample of the high aluminate mix cured at $60{ }^{\circ} \mathrm{C}$ with 500 times magnification. 


\subsection{CONCLUSIONS}

This study has resulted in the following conclusions:

1 The saturated liquid permeability (in terms of hydraulic conductivity) of Saltstone mixes depends significantly on the curing temperature. As the curing temperature increases, the hydraulic conductivity can increase over three orders of magnitude from roughly $10^{-9} \mathrm{~cm} / \mathrm{sec}$ to $10^{-6} \mathrm{~cm} / \mathrm{sec}$ over the temperature range of $20^{\circ} \mathrm{C}$ to $80^{\circ} \mathrm{C}$.

2 Although an increased aluminate concentration (at $0.22 \mathrm{M}$ ) in the ARP/MCU waste stream improves (decreases) saturated permeability for samples cured at lower temperatures, the permeability for samples cured at $60{ }^{\circ} \mathrm{C}$ to $80^{\circ} \mathrm{C}$ is the same as the permeability measured for the same mix with low aluminate concentration.

3 Measurements of dynamic Young's moduli (E) for these mixes reveal a correlation between $\mathrm{E}$ and hydraulic conductivity. Therefore, it is possible to use $\mathrm{E}$ values to estimate the values of hydraulic conductivity. The measurement of $\mathrm{E}$ is much easier than measuring permeability of Saltstone mixes and has the added advantage of readily measuring the time dependence of the performance property.

$4 \quad$ The UFA system can be used to measure hydraulic conductivity of Saltstone samples. The permeability results obtained using the UFA centrifuge system agreed within experimental error to the permeameter results obtained for the same mixes at MACTEC. In particular the UFA technique is suitable for the range of hydraulic conductivities between $10^{-10} \mathrm{~cm} / \mathrm{sec}$ to $10^{-6} \mathrm{~cm} / \mathrm{sec}$.

5 The changes in permeability as a function of curing temperature appear to be related to microstructural changes in the cured Saltstone mixes. Backscattered electron microscopy images showed significant differences between the samples cured at different temperatures. 


\subsection{ACKNOWLEDGMENTS}

The authors would like to thank Kevin Hera of SRNL, who designed and oversaw the fabrication of the stainless steel holders for the UFA system. SEM images were obtained at Clemson University by David Wingard.

\subsection{PATH FORWARD}

The results in this report provide the basis for permeability changes at fixed curing temperatures. The next step is to consider the impact of kinetics on the permeability of Saltstone. To do this, one has to know the time/temperature profile conditions under which the Saltstone will be cured. This will require thermal modeling and/or actual time/temperature profiles within the vaults under various pour schedules to determine (1) an average profile of time and temperature under normal processing and (2) a conservative (worst case) profile. Samples can then be cast and cured in the laboratory under these time and temperature profiles prior to measurement of the permeabilities and E values and capture of the SEM images.

The hydraulic conductivity values on the high aluminate mixes should be measured using the UFA system and compared to the MACTEC results. Additional SEM data and analyses are required to better understand the differences in microstructures at various curing temperatures. 


\subsection{REFERENCES}

[1] Impact of Time/Temperature Curing Conditions and Aluminate Concentration on Saltstone Properties, J. R. Harbour, T. B. Edwards and V. J. Williams, SRNL-STI-2009-00184, Rev. 0.

[2] Key Factors that influence the Performance Properties of ARP/MCU Saltstone Mixes, J. R. Harbour, T. B. Edwards, and V. J. Williams, SRNL-STI-2009-00546, Rev. 0, 2009

[3] Saltstone Performance Indicator, J. R. Harbour and V. J. Williams, SRNL-STI-200800488, Rev. 0, December 2008.

[4] Performance Properties of Saltstone Produced Using SWPF Simulants, J. R. Harbour and T. B. Edwards, SRNL-STI-2009-00810, Rev. 0, December 2009.

[5] Hydraulic and Physical Properties of ARP/MCU Saltstone Grout, K. Dixon, J. Harbour and M. Phifer, SRNL-STI-2009-00419, Rev. 0, March 2010.

[6] Impact of Curing Temperature on Performance Properties of Cementitious Waste Forms, J. R. Harbour, SRNL-RP-2010-00860, Rev. 0, April 2010.

[7] Measurement of Hydraulic Conductivity and Young's Modulus for ARP/MCU Mixes as a Function of Key Operational/Compositional Factors, J. R. Harbour and T. B. Edwards, SRNLRP-2010-00852, Rev. 0, April 2010.

[8] What is Needed in a Permeability Test for Evaluation of Concrete Quality? R. D. Hooton, in: L.R. Roberts, J.P. Skalny (Eds.), Pore Structure and Permeability of Cementitious Materials, Vol. 137, Materials Research Society, Pittsburgh, PA, 1989, pp. 141-149.

[9] Permeability of Saltstone, J. R. Harbour, T. B. Edwards, V. J. Williams, D. M. Feliciano and G. W. Scherer WSRC-STI-2007-00437, Rev. 0, 2007. 